\title{
Article \\ Can a priori unknown values of biomechanical parameters be determined with sufficient accuracy in MBS using sensitivity analysis? Analyzing the interaction characteristics between cervical vertebra and pedicle screw
}

\author{
Ivanna Kramer ${ }^{1, \ddagger}(\mathbb{D}$, Sabine Bauer $2, \ddagger$ \\ 1 Institute for Computational Visualistics, University Koblenz-Landau, Koblenz, Germany; \\ ivannamyckhal@uni-koblenz.de \\ 2 Institute of Medical Technology and Information Processing, UniversityKoblenz-Landau, Koblenz, Germany; \\ bauer@uni-koblenz.de \\ * Correspondence: bauer@uni-koblenz.de \\ $\ddagger$ These authors contributed equally to this work.
}

check for updates

Citation: Kramer, I.; Bauer, S. Can a priori unknown values of biomechanical parameters be determined with sufficient accuracy in a MBS using sensitivity analysis? Analyzing the interaction characteristics between cervical vertebra and pedicle screw. Preprints 2022, 1, 0. https://doi.org/

Publisher's Note: MDPI stays neutral with regard to jurisdictional claims in published maps and institutional affiliations.

Copyright: (c) 2022 by the authors Licensee MDPI, Basel, Switzerland. This article is an open access article distributed under the terms and conditions of the Creative Commons Attribution (CC BY) license (https:// creativecommons.org/licenses/by/ $4.0 /)$.

\begin{abstract}
Finite element (FE) modeling is commonly used as a method to investigate the influence of medical devices, such as implants and screws and their effects on the biomechanical behavior of the spine. Another simulation method is a multi-body simulation (MBS), where the model is composed of several non-deformable bodies. MBS solvers generally require a very short computing time for dynamic tasks compared to an FE analysis. Considering this computational advantage, in this study, we examine whether parameters whose values are not known a priory can be determined with sufficient accuracy using MBS model. Therefore, we propose a Many-at-a-time sensitivity analysis method that allows approximating these a priory unknown parameters without requiring long simulation times. This method enables a high degree of MBS model optimization to be achieved in an iterative process. The sensitivity analysis method is applied to a simplified screw-vertebra model, consisting of an anterior anchor implant screw and vertebral body of C4. An experiment described in the literature is used as a basis for developing and assessing the potential of the method for sensitivity analysis and to validate the models action. The optimal model parameters for the MBS model were determined to be $c=823224 \mathrm{~N} / \mathrm{m}$ for stiffness and $d=488 \mathrm{Ns} / \mathrm{m}$ for damping. The presented method of parameter identification can be used in studies including more complex MBS spine models or to set initial parameter values that are not available as initial values for FE models.
\end{abstract}

Keywords: multibody simulation; multi-way sensitivity analysis; spinal implant anchor screw; stiffness and damping parameters

\section{Introduction}

Serious trauma, tumors, osteoporosis or inflammatory processes can damage one or more vertebral bodies to such an extent that they are no longer stable. With such massive damage, instabilities and narrowing of the spinal canal often occur. To stabilize the spine, to prevent irreversible neurological lesions and to reduce the pain of the patient, the affected vertebral bodies are removed and a vertebral body replacement implant is inserted. As anterior implant placements are considered less traumatic and cause less complications than the posterior implant placements, anterior cervical intervertebral body cages combined with plates are commonly used to address these disorders [1].

In various experimental studies the biomechanical behavior of spinal posterior and anterior pedicle screws are analysed. According to Naoum et all [2] the applications of FE modeling in the spine have contributed to the understanding of bone biomechanics, both in healthy and abnormal conditions, such as scoliosis, fractures, degenerative disc disease and osteoporosis. Rosa et all [3] aimed to verify the pullout resistance of lumbar pedicle screws obtained by the process of additive manufacturing and to compare them with the screws obtained with traditional techniques. 
The experimental study of Kotekir et all [4] included both radiological and anatomical investigations to explore the feasibility of anterior transpedicular screw (ATPS) fixation of cervical spine. Further, the morphological measurements for technical requirements were obtained and the accuracy of the ATPS was evaluated using fluoroscopy. To assess the relationship of screw pullout and screw insertional torque across a wide range of bone mineral densities (BMD) Reitman et all [5] analysed the correlation between screw pullout strength and BMD. The objectives of Koller et all [6] were to assess the ex vivo accuracy of placing ATPS into the cervical vertebra as well as the biomechanical performance of ATPS in comparison to traditional vertebral body screws in terms of pullout strength. Another possibility to analyze the interaction of human spinal structures and medical devices is the finite element (FE) modeling. Compared to experiments, FE models provide the opportunity to document related mechanical responses during simulation [7]. There is a variety of FE studies that investigated load situations of healthy spines and the effect of spinal stabilization devices of lumbar spine segments. Mas et all [8] designed a FE model of the lumbar spine to compare differences in the biomechanical behaviour between a healthy spine and a spine with two different fixation systems inserted at L4-L5 level. The study of Schmidt et all [9] focused on the determination of stiffness values for posterior stabilization devices achieving a flexible, semi-flexible or rigid connection between vertebra L4 and L5 by a FE model. While the study of Goel et all [10] determined the effects of a specific disc implant (Charité artificial disc) across the implanted and adjacent segments, the focus of Schmidt et all [9] was to determine stiffness values of posterior stabilization devices achieving a flexible, semi-flexible or rigid connection between vertebra L4 and L5 by a FE model.

The analysis of the motion behavior of cervical spinal implants was investigated by Sun et all [11] and Galbusera et all [12] via FE simulation. Sun et all [11] investigated the biomechanical behavior of the cervical spine after implanting different interbody fusion cages. FE models of C4-C7 segments were built to determine the segmental principal ranges of motion and the load shared by the interbody cage. The investigations of Becker et all [7] and Liu et all [13] specializes in analysis of screw-bone interaction. The bone is modeled in a simplified way, as a rectangle, with corresponding material characteristics of the cortical and spongious bone [7] and as an alternative test medium consisting of two different types of polyurethane foam [13].

The focus of the following studies has been the analysis of mechanical properties of the screws-vertebra structure and the effects of traditional and cortical bone trajectory pedicle systems. Abbeele et all [14] predicted the intraoperative pullout strength through a patient-specific FE model of a standard cylindrical pedicle screw inserted in the lumbar vertebra. The impact of different screw sizes on pedicle screw fixation in osteoporotic vertebrae was quantitatively determined using FE simulation by Keitaro et all [15]. The aim of the study of Qi et all [16] was to explore the relationship between pedicle screw pullout strength and screw diameter by FE analysis. Xu et all [17] created a lumbar spine FE model instrumented with pedicle screws and rods to identify the limitations and advantages of the three types of screw-bone connection models. In this study only static loading conditions were tested. Su et al [18] investigated the effects of the traditional pedicle screw and cortical bone trajectory screw implantation on the lumbar spine using FE methods. The results showed that there was no significant difference in the structural stability of the lumbar spine model between the traditional pedicle screw system and the cortical bone trajectory system. However, the trajectory of the cortical bone can reduce endplate loading.

Several FE studies have assessed characteristics in screw failure and discussed the typical internal stress distribution. Senale et all [19] aimed to investigate the biomechanical influence of the screw's size, geometry, and bone density of instrumentation for the treatment of ankylosing spondylitis cervical spine fractures (ASCF). Therefore patient-specific FE models of the lumbar vertebra implanted with two pedicle screws were created. The research of Somtual et all [20] analyzed the failure of pedicle screw fixation implemented in a cervical spine vertebra under the screw pullout process. Nine pedicle screw FE models 
were created and the results were compared using stress transfer parameter of each screw to show how the screws' parameters affected the pullout strength. Wu et all [1] used a FE model of the lower cervical spine to compare the biomechanical properties of a novel anterior transpedicular screw artificial vertebral body system (AVBS) with a conventional anterior screw plate system (ASPS) that fixes the lower cervical spine. The characterization of failure of posterior bone screw during screw pullout process using FE analysis was focused by Ritddech et all [21]. They investigated the different screw parameters, outer diameter, core diameter and larger proximal root radius, affecting screw pullout strength.

Although FE models are able to deal with stresses, deformations and complex material behavior, they require a high computational time [22]. The study of Bonnheim et all [23] included a CT-based FE analysis of a vertebral body implanted with prosthetic disc implants of various sizes and stiffness. The model was loaded with compression- and flexion-induced anterior impingement. It is reported that this typical analysis utilized 1100 processors, 3000 GB of memory, and required over 200 CPU hours. Also Keitaro et all [15] reported a computer solution time per simulation of 12-36 hours to analyze the impact of screw diameter and length on pedicle screw fixation strength in osteoporotic vertebrae via a lumbar FE screw-vertebra model. Moreover, the above mentioned FE models are very specifically tailored to an explicit implant and screw design. Out of the published results, no generally valid statements can be made for other implant and screw types. It is certain that the screw design influence the pullout resistance [16]. In particular, the screw length and the screw diameter impacts the pullout strength [24]. The screw design of our present study differs considerably from the screw designs available in the literature. While screw lengths of 30-50.74mm and screw diameter of 3.5-5.5mm [4], [7], [13], [16], [15] were examine in the literature, the examined screw in this study has a screw length of $17 \mathrm{~mm}$ and a screw diameter of $1.7 \mathrm{~mm}$.

In the current research there is no existing direct way to measure biomechanical properties such as stiffness and damping of the screw inserted in a human spine in vivo. In the most cases, those parameters are inferred using pullout experiments on cadaver or animal vertebrae [25-27]. A few approaches that apply optimization methods are proposed in the literature to identify the stiffness and damping values for the various spinal flexible structures [28,29]. Rohlmann et al. [30] determined an optimal stiffness of the solid longitudinal rods in the pedicle-screw-based implant applying optimization criteria defined upon the ranges of motion as well as loads in the facet joints, bulgings of the intervertebral disc and the intradiscal pressure in the FE model of the lumbar spine. To our knowledge, no current study deals with the calculation of unidentified biomechanical parameters of the spinal screw using MBS models.

Therefore, we propose a sensitivity method for MBS models with which a priori unknown parameters can be approximated without the need of longer simulation times. In this study, a simplified screw-vertebra model is used in order to simultaneously exchange the model parameters and calculate the effects of said parameters. The main focus is on determining stiffness and damping characteristics for an analysis of the interaction between the implant anchor screw and the vertebral body.

\section{Methods}

The multibody simulations were performed using Simpack 2021x (Dassault Systèmes Simulia GmbH, Germany).

\subsection{Model Structure and Model Parameters}

The three-dimensional MBS model consists of vertebra C4 and an anchor screw of the cervical spine vertebral body replacement implant MediExpand. The anchor screw represents the connection between the implant and the vertebra and fixates the implant to the corresponding vertebra. The MBS model of the anchor screw was designed using the CAD-software Catia. The material of the screw is a titanium alloy. The anchor screw 
was placed in the vertebra in such a way that it has its intended position for fixing the vertebral body replacement. The diameter of the screw was $2.7 \mathrm{~mm}$ and its total length $17 \mathrm{~mm}$ from the top to the tip of the screw (see Figure 1). Detailed information about further mass properties of the anchor screw can be found in Table 1.

The vertebra is rigidly connected to the global reference system so that no residual mobility was possible. The anchor screw, on the other hand, has 6 degrees of freedom, so that it could perform translational movements in the directions $\mathrm{x}, \mathrm{y}$ and $\mathrm{z}$ and rotations around axes $\mathrm{x}, \mathrm{y}$ and $\mathrm{z}$ with respect to the vertebra. The force application point of the pullout force was located centrally at the end of the anchor screw head, so that the pullout force was gradually applied to the screw head along the screw axis. Pezowicz et all [25] expressed the stability of bone screw embedment in the cervical vertebral body as the force that can pullout the screw from the vertebra. Therefore, to determine the effects of translational interaction parameters, different longitudinal extraction forces were applied to the screw head. Starting with $0 \mathrm{~N}$, the force was successively increased linear until it reached an approximate average pullout force of $411 \mathrm{~N}$.

\subsection{Biomechanical Characteristic of the Model}

The biomechanical behavior of the screw-vertebra interaction is described by a generalized 3D matrix force element (see eq. 1) provided by the simulation software and adapted to our simulation case. The forces $F_{x}, F_{y}, F_{z}$ and torques $T_{\alpha}, T_{\beta}, T_{\gamma}$ interact between two defined points, one on the screw (interaction screw point) and one on the vertebra (interaction vertebra point), in multiple axis directions, i.e. the three translations as well as the three rotations. The corresponding force and torque equation is determined by a stiffness term $c_{x}, c_{y}, c_{z} \times x_{F}, y_{F}, z_{F} ; c_{\alpha}, c_{\beta}, c_{\gamma} \times \alpha_{T}, \beta_{T}, \gamma_{T}$ and damping term $d_{x}, d_{y}, d_{z} \times \dot{x}, \dot{y}, \dot{z} ;$ $d_{\alpha}, d_{\beta}, d_{\gamma} \times \dot{\alpha}_{T}, \dot{\beta}_{T}, \dot{\gamma}_{T}$. Variable $c$ defines the stiffness and $d$ the damping constants in the three coordinate axis directions. The distance between the two interaction points is represented by the variables $x, y, z$ and the velocity of the interaction screw point by $\dot{x}, \dot{y}, \dot{z}$. The variables $\alpha, \beta$ and $\gamma$ indicate the current angle between the axis of rotations and $\dot{\alpha}_{T}, \dot{\beta}_{T}, \dot{\gamma}_{T}$ the angle velocity of the interacting screw and vertebra (see Equation 1).

$$
\left(\begin{array}{c}
F_{x} \\
F_{y} \\
F_{z} \\
T_{\alpha} \\
T_{\beta} \\
T_{\gamma}
\end{array}\right)=\left(\begin{array}{c}
c_{x} x_{F}+d_{x} \dot{x} \\
c_{y} y_{F}+d_{y} \dot{y} \\
c_{z} z_{F}+d_{z} \dot{z} \\
c_{\alpha} \alpha_{T}+d_{\alpha} \dot{\alpha}_{T} \\
c_{\beta} \beta_{T}+d_{\beta} \dot{\beta}_{T} \\
c_{\gamma} \gamma_{T}+d_{\gamma} \dot{\gamma}_{T}
\end{array}\right)
$$

The matrix force element contains only diagonal coefficients as there is no crosscoupling between the directions.

The basic idea to determine the translational stiffness and damping characteristics of the screw-vertebra interaction is to induce a state of equilibrium in which the interaction force exerts just enough reaction force on the pullout force, so that the screw performs almost no translational and rotational movement. To realize this, the stiffness and damping parameters have to be initially determined in such a way that the interaction force that counteracts the pullout force prevents the screw from slipping out of the vertebral body. It is possible that the screw still moves from its position irrespective of the stiffness. Diminishing such unintentional vibrations is extremely challenging [31]. Unwanted vibrations can be suppressed by taking into account the damping term. However, if a damping value is selected too high, the damping term will dominate the force equation and stiffness will have a minor or no influence on the force characteristic. Therefore, the smallest possible and accurate damping parameter has to be determined, so that oscillation and over-damping is prevented. 


\subsection{Model Validation}

The main objective of the numerical model validation was the verification of the correctness of the model responses with respect to the available real data or to the outcome of existing validated models. Generally, the behavior of screw-vertebra simulation models is validated against experimental force-displacement measurements carried out from pullout tests [32,33]. In order to ensure that such a real scenario can be validly reproduced using multibody simulation and that an entered non-linear stiffness can be correctly processed in the current model, the experimental test of Pezowicz et all [25] was modeled. Their experimental tests were performed on vertebrae obtained from cadaverous specimens from the cervical spine. A screw inserted into the vertebra was pulled along the screw axis at a constant speed of $2 \mathrm{~mm} / \mathrm{min}$. Changes in the force $F[N]$ in relation to the displacement $d[\mathrm{~mm}]$ of the screw in the direction of the applied constant speed were recorded during the tests. The aim of the validation step was to reproduce the sample progress for the screw in our model represented by a load-displacement curve similar to that of the experimental test of Pezowicz et all [25]. The vertebra was fixed in the model to prevent movement. The connection between the vertebra and the screw was defined by a single axis of translation with constant velocity along the $y$-axis to ensure that the pullout force creates a constant screw velocity.

The biomechanical behavior between screw and vertebra was described by nonlinear, two-dimensional force-displacement characteristics. Figure 3 shows that with the model setup and configuration, results of Pezowicz et all [25] could be reproduced almost exactly when the screw is pulled with a constant velocity.

For the validation of our model against existing numerical screw-vertebra models quantitative comparison was difficult to obtain for the following reason: to the best of our knowledge, no numerical study has been done yet involving the screw design presented in this study.

\subsection{Parameter Search Using Sensitivity Analysis}

Generally speaking, the aim of Sensitivity Analysis (SA) is to determine the level of model robustness by investigating the input parameters of the model [34]. In this study, the Many-at-a-time sensitivity analysis method, see the classification proposed by Saltelli et all [35], was used to estimate the optimal set of model parameters by analyzing their impact on model behavior.

Further, our goal was to find such $\left(c_{F}, d_{F}\right) \in C \times D$ so that the maximum $y$-translation, described by the function $\max (y)$, the maximum $\dot{y}$-velocity, described by the function $\max (\dot{y})$, are constrained by the predefined thresholds when the pullout force $F_{\text {pull }}$ is being exerted. Additionally, it was analyzed if the model reaches the static equilibrium state. According to Ozkaya et all [36], a body is in a static equilibrium when its linear or angular velocity as well as its acceleration are zero. To determine, at which time step in the simulation the screw comes to the rest, we investigate the time interval when the screw's velocity and the screw's acceleration start approaching zero. The problem can be expressed in the following equation:

$$
\begin{array}{ll}
\underset{c, d}{\operatorname{minimize}} & {\left[\begin{array}{l}
y \\
\dot{y} \\
\ddot{y}
\end{array}\right]=f(c, d)} \\
\text { subject to } & \max (y) \leqq \epsilon_{y}, \\
& \max (\dot{y}) \leqq \epsilon_{\dot{y}} \\
& \dot{y}_{e q} \leqq \epsilon_{\dot{y}_{e q}} \\
& \ddot{y}_{e q} \leqq \epsilon_{\ddot{y}_{e q}}
\end{array}
$$

where $f$ is the simulation function and $\epsilon_{y}, \epsilon_{\dot{y}}, \epsilon_{\ddot{y}}$ are thresholds specified in Table 2 .

The current SA method performs multiple simulations of the screw-vertebra model described in Sec.2.1 and afterwards applies Equation 2 in a two-step parameter search in 
order to determine $\left(c_{F}, d_{F}\right)$. Figure 4 demonstrates the workflow of the SE method used in this study. In the first step of the proposed method, the pairs of parameters are obtained increasing exponentially an initial value $b \in N$. The resulting parameter sets were then built as follows: $D=\left\{b^{2}, b^{3}, b^{4}, b^{5}, b^{6}\right\}$ and $C=\left\{b^{3}, b^{4}, b^{5}, b^{6}, b^{7}\right\}$. We had chosen different starting values for the exponent of the base $b$ to prevent over-damping of the system. Because if a damping value is selected that is too high, the damping term dominates the force Equation 1 and the stiffness has a minor or no influence on the force characteristic. Therefore, the starting values for the exponent of the damping were chosen to be smaller then the stiffness exponents.

In the next step of the proposed parameter search pipeline, a region of interest (RoI) within the parameter sets $C$ and $D$ was determined. To that end, for each parameters pair $\left(c_{i}, d_{i}\right) \in C \times D$ a model simulation was performed. The simulation output containing the maximum translation $\max (y)$ and maximum velocity $\max (\dot{y})$, as well as screw velocity $\dot{y}_{t}$ and acceleration $\ddot{y}_{t}$ calculated for every time step, was then analyzed. The upper and lower bounds of the RoI were defined in such a way, that the conditions described in Equation 2 can be hold and the damping and stiffness constants was small.

The last step of the current approach applied the lower and upper RoI bounds into the search procedure to find the optimal input parameters $c$ and $d$. In order to avoid an exhausting search covering all possible combinations of parameters included in the RoI, a nested binary search for both $c$ and $d$ was utilized. This commonly used procedure repeatedly divides the search interval into two equidistant sub-intervals and starts searching in the middle of the parameters list until the optimal parameters are found or the search interval is empty. In each loop iteration, the model simulation was performed applying the current parameters pair and the outcome was analyzed against imposed thresholds defined in Table 2.

\section{Results}

The bar charts shown in Figure 5 and in Figure 6 represent the maximum and average screw translation calculated in the simulation for the pullout force of $411 \mathrm{~N}$ using defined pairs of stiffness and damping values. It can be seen from the diagram in Figure 5 that high screw displacements are achieved for the parameter combination values $c=1.56 \times 10^{4} \mathrm{~N} / \mathrm{m}$ to $3.91 \times 10^{5} \mathrm{~N} / \mathrm{m}$ and $d=6.25 \times 10^{2} \mathrm{Ns} / \mathrm{m}$ to $3.91 \times 10^{5} \mathrm{Ns} / \mathrm{m}$ with a displacement between $y_{\max }=2.63 \times 10^{-2} \mathrm{~m}$ and $y_{\max }=9.10 \times 10^{-4} \mathrm{~m}$. The highest screw displacement of $y_{\max }=2.63 \times 10^{-2} \mathrm{~m}$ is reached with the parameter values $c=1.56 \times 10^{4} \mathrm{~N} / \mathrm{m}$ and $d=6.25 \times 10^{2} \mathrm{Ns} / \mathrm{m}$. Both diagrams in Figure 5 and Figure 6 show that the values of the maximum displacement do not deviate much from the average translations. The system outcome indicates the general stability of the presented model.

The maximum and the average screw velocities are shown in Figure 7 and in Figure 8. From the presented results it can be seen that the highest velocity values are reached by the screw with a relatively small stiffness term of $1.56 \times 10^{4} \mathrm{~N} / \mathrm{m}$ and damping values $d \in\left[6.25 \times 10^{4} \mathrm{Ns} / \mathrm{m}, 1.56 \times 10^{4} \mathrm{Ns} / \mathrm{m}, 3.91 \times 10^{4} \mathrm{Ns} / \mathrm{m}\right]$. The maximum screw velocity of $\dot{y}_{\text {max }}=1.60 \times 10^{-2} \mathrm{~m} / \mathrm{s}$ is achieved with a parameter combination of $c=1.56 \times 10^{4} \mathrm{~N} / \mathrm{m}$ and $d=1.56 \times 10^{4} \mathrm{Ns} / \mathrm{m}$.

The deviations of the maximum screw velocity from its average values are comparatively greater than what was shown in case of screw displacement. When the stiffness term increases from $3.91 \times 10^{5} \mathrm{~N} / m$ up to $6.10 \times 10^{9} \mathrm{~N} / \mathrm{m}$, and for damping terms up to $3.91 \times$ $10^{4} \mathrm{Ns} / \mathrm{m}$, the maximum velocity deviates further from its average values than in any other parameter sets.

Another parameter that was analyzed within the scope of this study was the time needed for the system to reach a static equilibrium. For the determination of the equilibrium state the velocity of the screw was compared in each time step until the simulation's end. We considered the rest state to be reached from the point the velocity of the screw was continuously smaller then the pre-defined constrain $\epsilon_{\dot{y}_{t}}$. It is shown in Figure 9, that no equilibrium state could be reached when damping values dominate stiffness coefficients. 
The only exceptions were the simulation runs with the maximum damping term of $d=$ $2.44 \times 10^{8} \mathrm{Ns} / \mathrm{m}$, where the system could reach the rest state very short time of $2 \times 10^{-5} \mathrm{~s}$. The same model behaviour is observed for large stiffness of $c=2.44 \times 10^{8} \mathrm{~N} / \mathrm{m}$ and $c=6.10 \times 10^{9} \mathrm{~N} / \mathrm{m}$.

The obtained results show, that high stiffness and damping values guarantee reaching screw equilibrium state. However, the goal of this study is to find the smallest values of the input model parameters that bring the screw into a resting state and do not violate the translational constrain $\max (y)<\epsilon_{y}$. Therefore, the Region of Interest (RoI) for the fine-grained parameter search was chosen to be $c \in\left\{3.91 \times 10^{5} \mathrm{~N} / \mathrm{m}, \ldots, 9.77 \times 10^{6} \mathrm{~N} / \mathrm{m}\right\}$ and $d \in\left\{0 \mathrm{Ns} / \mathrm{m}, \ldots, 1.56 \times 10^{4} \mathrm{Ns} / \mathrm{m}\right\}$.

With the initial set of parameters, the search of the general influence of the stiffness and damping parameter is analyzed and the RoI is defined. We determined the RoI analytically by comparing the model translation, its velocity and the time it took to reach equilibrium. Since our goal is to find the minimum damping and stiffness coefficients, that fit the requirements from Equation 2, the selected RoI is defined by its boundaries: $c_{\text {lower }}=$ $3.91 \times 10^{5} \mathrm{~N} / \mathrm{m}, c_{\text {upper }}=9.77 \times 10^{6} \mathrm{~N} / \mathrm{m}$ and $d_{\text {lower }}=0 \mathrm{Ns} / \mathrm{m}$ and $d_{\text {upper }}=1.56 \times 10^{4} \mathrm{Ns} / \mathrm{m}$. The RoI is highlighted in Figure 5, Figure 6, Figure 7 as well as 8 and Figure 9 with a blue border.

After the RoI has been determined, the optimal parameters for $c$ and $d$ can be found using a binary search method in order to reduce long computing times in case when the parameters values would be determined linearly within the selected RoI. In the current implementation of the binary search we monitor the simulation outcome in each loop iteration in order to find aforementioned smallest $c$ and $d$, which have significant impact on the screw translation and velocity. When at least one set of parameters was found and no changes are indicated in the model response for two consecutive parameter pairs, the search is stopped.

The results of the parameter determination using a binary search method are presented in Figure 10, where the distribution of stiffness and damping values with regard to screw translation is pictured. It can be observed that for the damping values $d<7813 \mathrm{Ns} / \mathrm{m}$ the majority of identified stiffness coefficients are distributed between $6 \times 10^{5} \mathrm{~N} / \mathrm{m}$ and $9 \times 10^{5} \mathrm{~N} / \mathrm{m}$. Withing this parameter interval the maximum screw displacement of $6.78 \times$ $10^{-4} \mathrm{~m}$ is reached. Through the combination of damping value $d=7813 \mathrm{Ns} / \mathrm{m}$ with the stiffness coefficient $c \geq 9 \times 10^{5} \mathrm{~N} / \mathrm{m}$ very small screw displacements up to $2.6 \times 10^{-4} \mathrm{~m}$ could be achieved. Another observation is that screw displacement data perfectly fit a curve defined by the third order polynomial equation:

$$
y=r+s * x+t * x^{2}+u * x^{3},
$$

where $r \approx 0.002, s \approx-3.0 \times 10^{-9}, t \approx 2.139 \times 10^{-15}$ and $u \approx-5.4 \times 10^{-22}$. The suitable fit of the regression curve shows a strong relation between stiffness term and screw translation. Using the determined parameters of the regression curve and a given stiffness value, the screw displacement can be estimated along the selected RoI.

In order to determine the final set of parameters we consider the screw displacement values that are on or below the purple line which represents the translation constraint $\epsilon_{y}$. What is evident is that a stiffness value of $c=823224 \mathrm{~N} / \mathrm{m}$ and a damping value of $d=488 \mathrm{Ns} / \mathrm{m}$ are found to be an optimal parameter pair, for which the sufficient maximum screw translation of $5.0 \times 10^{-4} \mathrm{~m}$ is reached.

We now look at simulation outcomes in terms of the maximum screw velocities that are shown in Figure 11. The maximum allowed velocity constraint from Table 2 is represented in the plot by a purple line. It can be seen that for the damping values $d \leqq 7813 \mathrm{Ns} / \mathrm{m}$ the corresponding stiffness coefficients that are sufficient to hold the pre-defined constraints are distributed in the interval of $c>7.5 \times 10^{5} \mathrm{~N} / \mathrm{m}$ and $c<1.6 \times 10^{6} \mathrm{~N} / \mathrm{m}$. Although the lowest screw velocity, which is marked red in the figure, is achieved at damping $d=7813 \mathrm{Ns} / \mathrm{m}$ and stiffness $c=1562499 \mathrm{~N} / \mathrm{m}$, the pair of minimum parameters is decided 
to be $c=823224 \mathrm{~N} / \mathrm{m}$ and $d=488 \mathrm{Ns} / \mathrm{m}$, which supports the above statement about the optimal parameter set found with regard to maximum screw translation. The maximal velocity for optimal $c$ and $d$ is highlighted using dark-blue color.

Results from Figure 11 show that velocity data points fit the separate regression curve for each damping term by applying the same polynomial from Equation 3 with different $r, s, t, u$ coefficients. In order to estimate the screw velocity, the stiffness term itself is not enough, with the damping term also has to be considered.

The time at which the screw reaches the static equilibrium state is plotted in Figure 13. The shortest time of $0.07674 \mathrm{~s}$ to reach the equilibrium state is guaranteed by $c=823224 \mathrm{~N} / \mathrm{m}$ and $d=488 \mathrm{Ns} / \mathrm{m}$. By applying the highest parameter values of $d=7813 \mathrm{Ns} / \mathrm{m}$ and $c=1562499 \mathrm{~N} / \mathrm{m}$ to the model, the screw enters rest state in $0.07908 \mathrm{~s}$ time.

The average CPU time per simulation was $5 \mathrm{~s}$.

\section{Discussion}

A basic requirement for a valid model is the adequate definition of model input parameters. Because model parameters are generally vague, their predictive power is frequently questioned [37]. A comprehensive sensitivity analysis is essential in order to stand firmly against these sensible critical arguments. Therefore, the aim of this study was the development of a sensitivity analysis method to identify valid input parameters for a highly simplified rigid body model composed of an implant screw and vertebral body C4. For this purpose, a two-steps sensitivity analysis was developed and applied to solve the parameter optimization problem: in the first step, the initial set of the stiffness and damping coefficients was created and model simulation for each pair of the parameter values was performed. Based on the obtained simulation results, the region of interest for further parameter search was determined. In the final step, the binary search with constraint checking was utilized in order to define the minimal input parameter values. The resulting optimal model parameters were found to be $c=823224 \mathrm{~N} / \mathrm{m}$ for the stiffness value and $d=488 \mathrm{Ns} / \mathrm{m}$ for the damping value. Parameters smaller than presented here were not analyzed a they did not indicate any significant change in neither screw velocity nor screw translation.

In case of specific simulation scenario when the input parameters are unavailable in literature and no possibility to conduct an experiment is given, the proposed method can be applied. Additionally, the obtained results can be used in more complex MBS and FE studies as valid model parameters for different degrees of abstraction models of the different spinal regions.

There are some limitations to this study, which can be divided into two categories: modelrelated and sensitivity-analysis-related limitations. The model-related limitation of the current model configuration is that only the elasticity in longitudinal direction of the screw has been taken into account. However, in real scenarios forces along the transverse and sagittal axes could also influence the screw. Furthermore, merely the transnational movement was examined. However, if one wants to capture the entire mechanical behavior between bone and screw, torques must also be taken into account, as they can act on the screw when present during load. Therefore, the elasticity of the "implant screw-bone" combination will be taken into account in the future work and analyzed in all spatial directions for transnational and also for rotational movements.

Another model-related limitation is that specific mass properties of a certain screw are included as model parameters that can influence the biomechanical behavior of the system. The analysis of the effects of mass properties such as mass, center of mass and inertia tensors on the model mechanics would provide further insights about the dependencies of model parameters. The analysis of effects of mass properties variations will be investigated in a future study.

The major sensitivity analysis limitation of the proposed approach is related to the search method used in this study in order to find the optimal input parameters. Although the binary search operation has been shown to be an effective method for finding the opti- 
mal parameters, it depends on how good the previously selected RoI is. Consequentially, it is important to define an adequate RoI where the desired behavior of the screw regarding its translation and velocity. In the proposed approach the boundaries of the RoI were selected manually by considering the results of the sensitivity analysis. However, this step can be automated by comparing simulation outcomes and defining conditions that describe the RoI. This is considered to be improved in a future work.

Despite the listed limitations, this study confirms the possibility of using multibody simulation as an adequate method for determining and analyzing biomechanical parameters. It shows that a real scenario, in this case a screw pullout test, could be reproduced by means of an MBS model and that the simulation results concur with the experimental ones. We furthermore demonstrated with our proposed method how sensitivity analysis can be used to define optimal model parameters.

In conclusion, it should be noted that this analysis should be seen as a part of our longstanding research focus. A MBS model of the spine is continuously developed for interactive advance planning of operative interventions. The idea is to develop a tool based on patient specific MBS model to make preoperative patient-specific statements about the load situation. Furthermore, with this MBS models there should be the possibility to simulate dynamic processes and thus to analyze the stress situation of the spinal structures during patient's daily activities.

In the systematic literature review of Alizadeh et all [38], concerning the biomechanical musculoskeletal models of the cervical spine, is described that the dynamic MBS seems more suitable to investigate the risk of injuries to the cervical spine in connection with occupational environments or effects, because of the lack of dynamic loading in the FE models. Despite the knowledge about load situation of spinal structures, which are provided by this sophisticated FE model structures, the basic load transfer behavior during dynamic movements remains initially unknown. Therefore, a holistic approach is intended to close this knowledge gap in the future. The idea is to create MBS models of the entire human body with a finely structured spinal model, with which stresses within spinal structures can be analyzed during movements in daily life. With this approach new insights into the influences of an inserted implant on the human body during dynamic scenarios can be obtained. The parameter search method proposed in this study can be used to define unknown biomechanical parameters describing characteristics of spinal structures as well as implants, especially in the case when the conducting in vivo experiments is impossible.

\section{Figures and Tables}

\begin{tabular}{|c|c|}
\hline \multicolumn{1}{|c|}{ mass properties } & value \\
\hline \hline mass [g] & 0.29 \\
\hline $\mathrm{CG} \mathrm{x}[\mathrm{mm}]$ & 0 \\
\hline $\mathrm{CG} \mathrm{y} \mathrm{[mm]}$ & -7.03 \\
\hline $\mathrm{CG} \mathrm{z}[\mathrm{mm}]$ & 0.0 \\
\hline main axis of inertia tensor in respect to CoM Ix $\left[\mathrm{g}^{*} \mathrm{~mm}^{2}\right]$ & $(1.0 / 0.00 / 0.00)$ \\
\hline main axis of inertia tensor in respect to CoM Iy $\left[\mathrm{g}^{*} \mathrm{~mm}^{2}\right]$ & $(0.00 / 0.96 / 0.28)$ \\
\hline main axis of inertia tensor in respect to CoM Iz $\left[\mathrm{g}^{*} \mathrm{~mm}^{2}\right]$ & $(0.00 /-0.28 / 0.96)$ \\
\hline screw length [mm] & 17.0 \\
\hline screw diameter $[\mathrm{mm}]$ & 2.7 \\
\hline
\end{tabular}

Table 1. Mass properties of the anchor screw. 


\begin{tabular}{|l|c|c|}
\hline Constrain definition & Notation & Value \\
\hline Threshold for screw translation $[\mathrm{m}]$ in $y$-direction & $\epsilon_{y}$ & $5 \times 10^{-4}$ \\
\hline Threshold for screw velocity [m/s] & $\epsilon_{\dot{y}}$ & $5 \times 10^{-5}$ \\
\hline Threshold for screw velocity in equilibrium state $[\mathrm{m} / \mathrm{s}]$ & $\epsilon_{\dot{y}_{e}}$ & $5 \times 10^{-8}$ \\
\hline Threshold for screw acceleration in equilibrium state $\left[\mathrm{m} / \mathrm{s}^{2}\right]$ & $\epsilon_{\dot{y}_{e}}$ & $5 \times 10^{-9}$ \\
\hline
\end{tabular}

Table 2. Thresholds applied to the parameter search: the values were obtained empirically so that the computing time for the search is optimized.

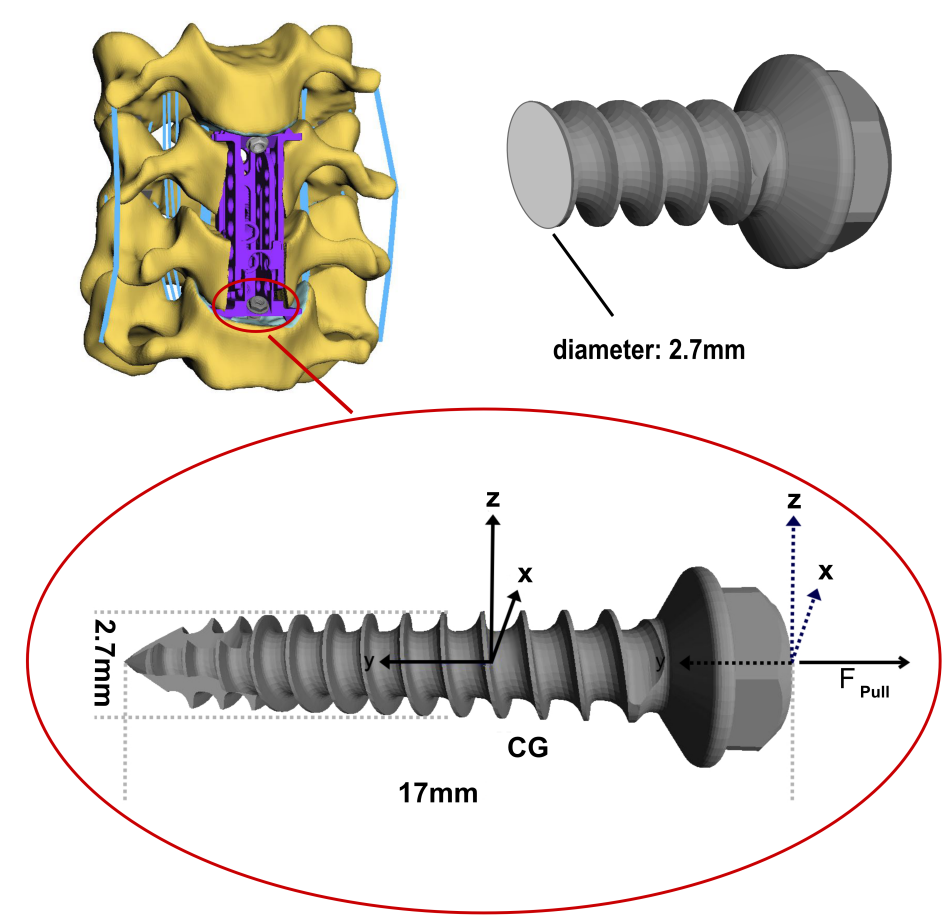

Figure 1. Attachment point of the lower anchor screw of the vertebral body replacement implants to the endplate of the 4 cervical vertebra (top left). Representation of the screw diameter (top right). Location of Center of Gravity (CG) and application point of the pullout force $F_{\text {pull }}$ of the anchor screw (button 


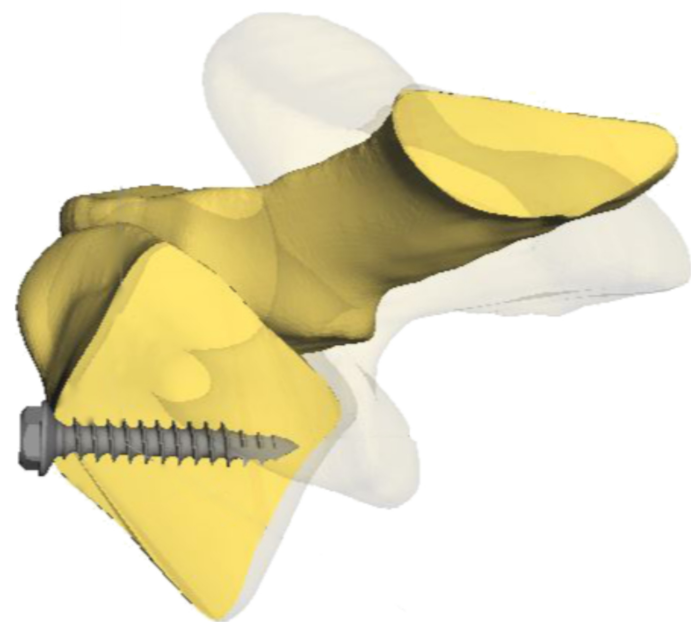

(A)

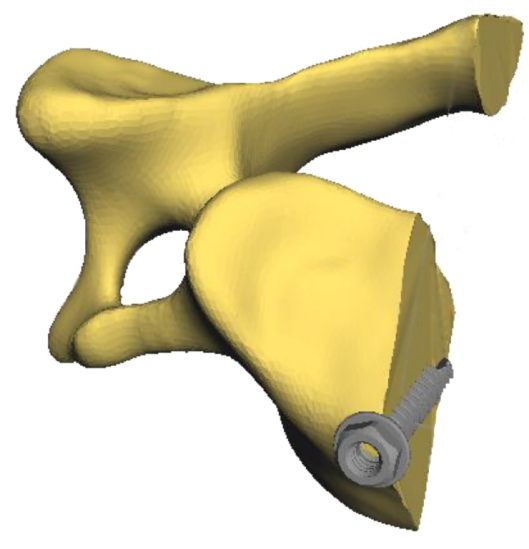

(B)

Figure 2. Different views of the screw fixed in C4 vertebra: lateral view of vertebra C4 with implemented screw (cross section) (A) and semi-top and lateral view of the screw-vertebra model (B).

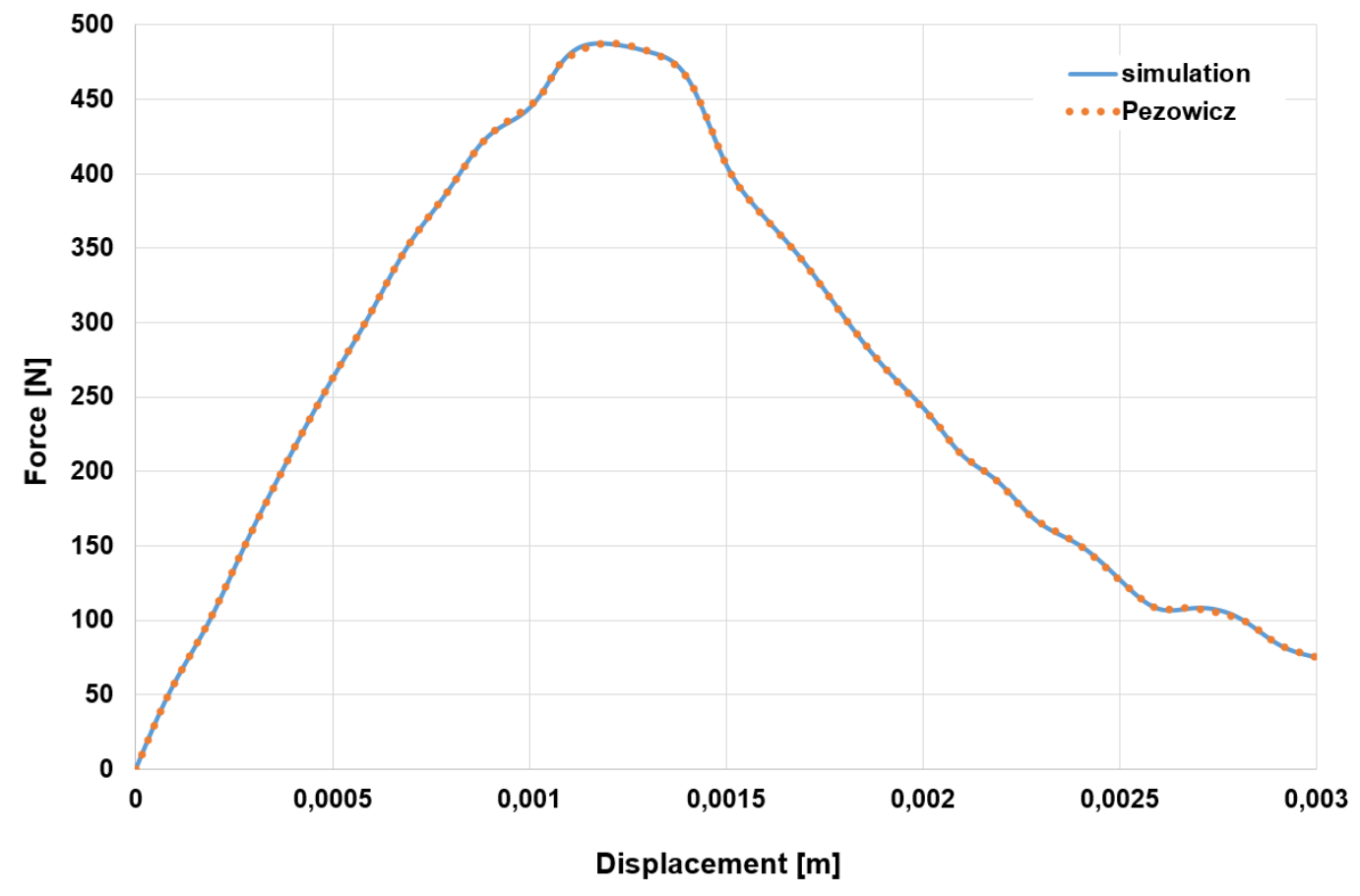

Figure 3. Comparison of the simulation result and experimental result of Pezowicz et all [25]: The results of the simulation are shown by the blue solid line and those of the experiment by the red dashed line. 


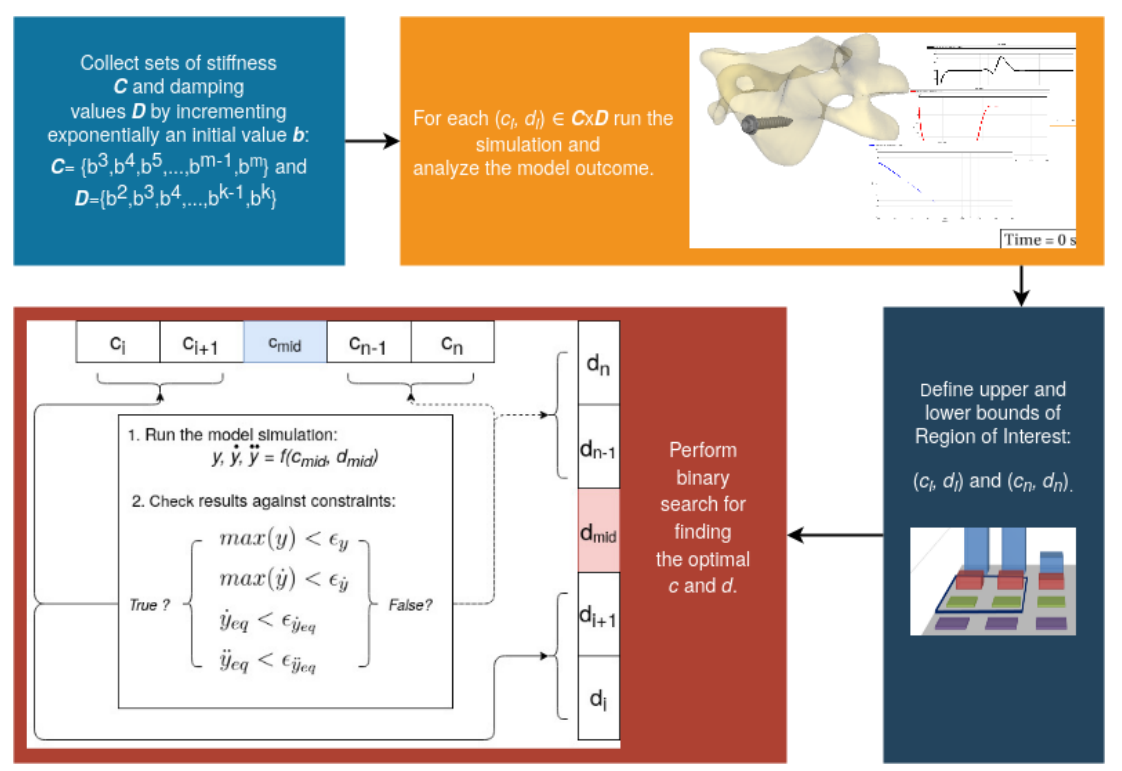

Figure 4. Workflow of the proposed parameter search.

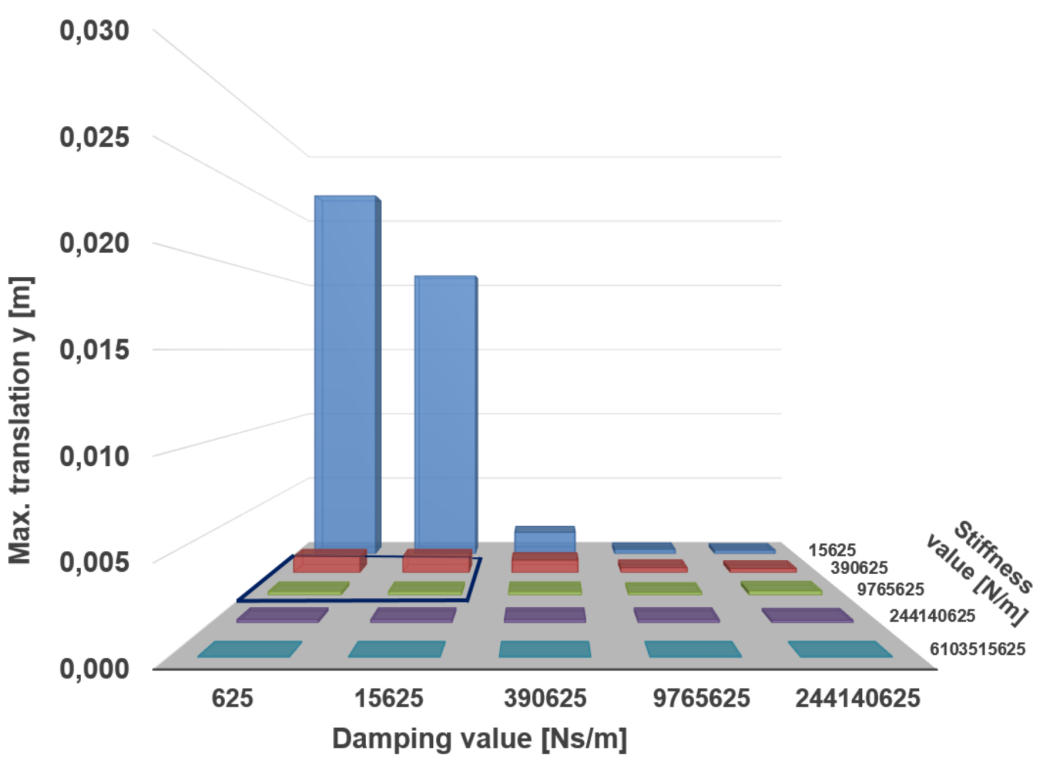

Figure 5. Maximum screw translation calculated for the initial parameters set with applied pullout force of $411 \mathrm{~N}$. The region of interest for $c \in\left\{3.91 \times 10^{5} \mathrm{~N} / \mathrm{m}, \ldots, 9.77 \times 10^{6} \mathrm{~N} / \mathrm{m}\right\} \mathrm{N} / \mathrm{m}$ and $\mathrm{d}$ $\in\left\{0 \mathrm{Ns} / \mathrm{m}, \ldots, 1.56 \times 10^{4} \mathrm{Ns} / \mathrm{m}\right\}$ is shown by a blue frame. 
0,030

0,025

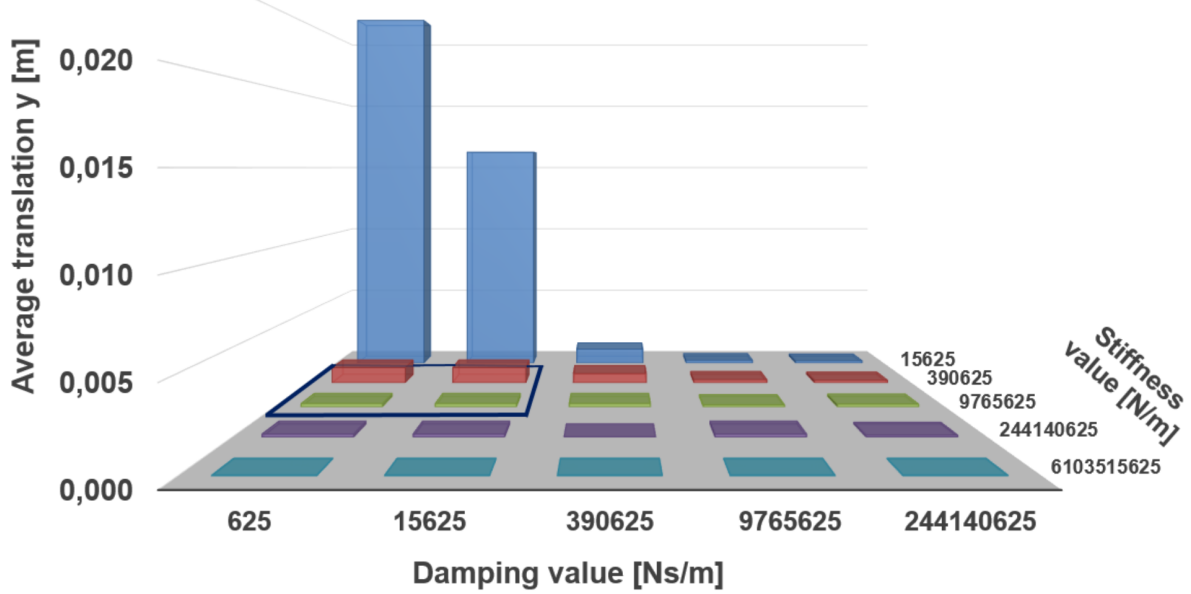

Figure 6. Average screw translation calculated for the initial parameters set with applied pullout force of $411 \mathrm{~N}$. The region of interest for $c \in\left\{3.91 \times 10^{5} \mathrm{~N} / \mathrm{m}, \ldots, 9.77 \times 10^{6} \mathrm{~N} / \mathrm{m}\right\} \mathrm{N} / \mathrm{m}$ and $\mathrm{d} \in\{0 \mathrm{Ns} / \mathrm{m}$, $\left.\ldots, 1.56 \times 10^{4} \mathrm{Ns} / \mathrm{m}\right\}$ is shown by a blue frame.

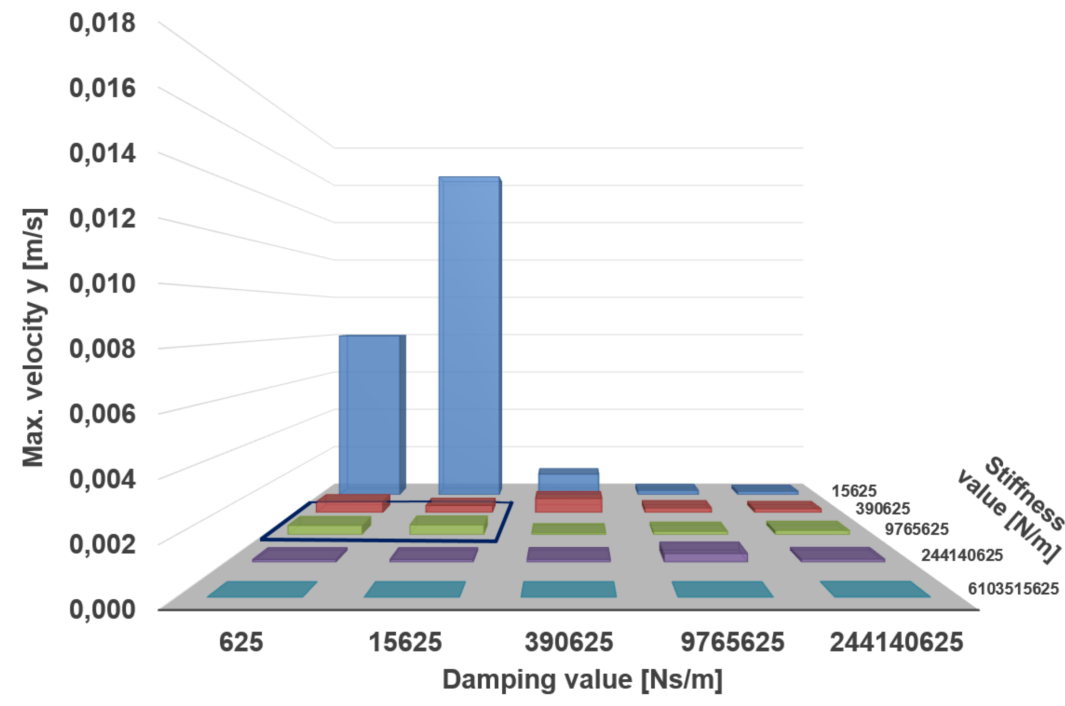

Figure 7. Maximum screw velocity calculated for the initial parameters set with applied pullout force of $411 \mathrm{~N}$. The region of interest for $c \in\left\{3.91 \times 10^{5} \mathrm{~N} / \mathrm{m}, \ldots, 9.77 \times 10^{6} \mathrm{~N} / \mathrm{m}\right\}$ and $d \in\left\{0 N s / m, \ldots, 1.56 \times 10^{4} \mathrm{Ns} / m\right\}$ is framed blue. 


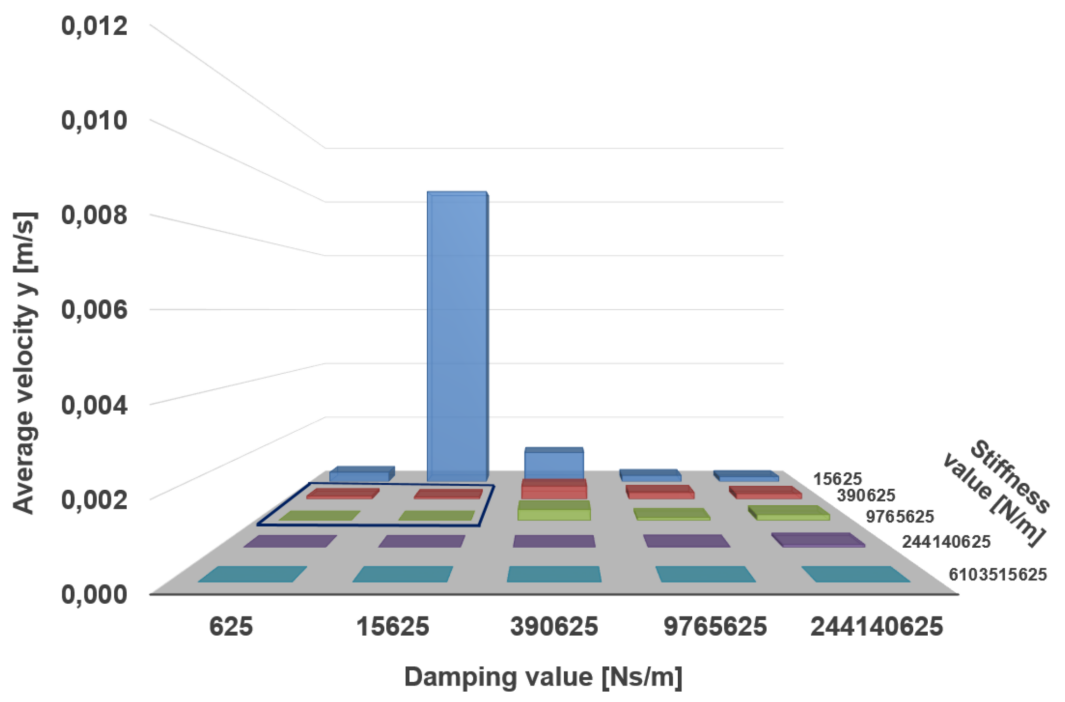

Figure 8. Average screw velocity calculated for the initial parameters set with applied pullout force of $411 \mathrm{~N}$. The region of interest for $c \in\left\{3.91 \times 10^{5} \mathrm{~N} / \mathrm{m}, \ldots, 9.77 \times 10^{6} \mathrm{~N} / \mathrm{m}\right\}$ and $d \in\{0 \mathrm{Ns} / \mathrm{m}, \ldots, 1.56 \times$ $\left.10^{4} \mathrm{Ns} / \mathrm{m}\right\}$ is framed blue.

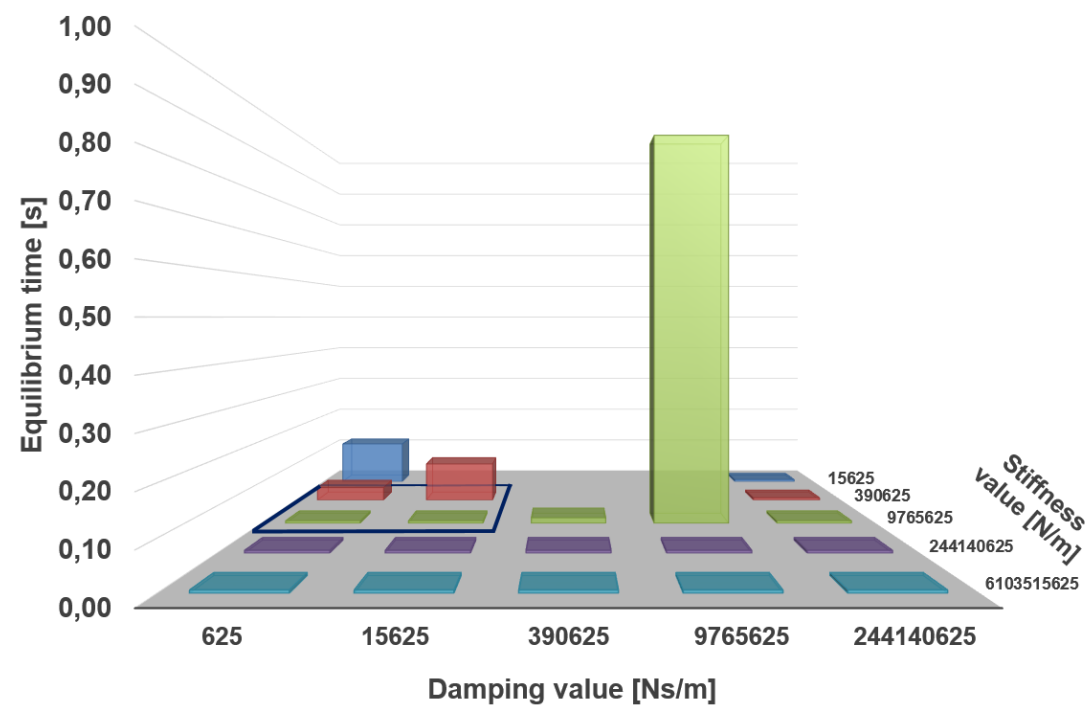

Figure 9. Time of reaching static equilibrium calculated for the initial parameters set with applied pullout force of $411 \mathrm{~N}$. The region of interest for $c \in\left\{3.91 \times 10^{5} \mathrm{~N} / \mathrm{m}, \ldots, 9.77 \times 10^{6} \mathrm{~N} / \mathrm{m}\right\}$ and $d \in$ $\left\{0 \mathrm{Ns} / \mathrm{m}, \ldots, 1.56 \times 10^{4} \mathrm{Ns} / \mathrm{m}\right\}$ is shown by a blue frame. For the value pairs stiffness and damping, for which no colored area can be seen at the corresponding point, a state of equilibrium was not reached. 


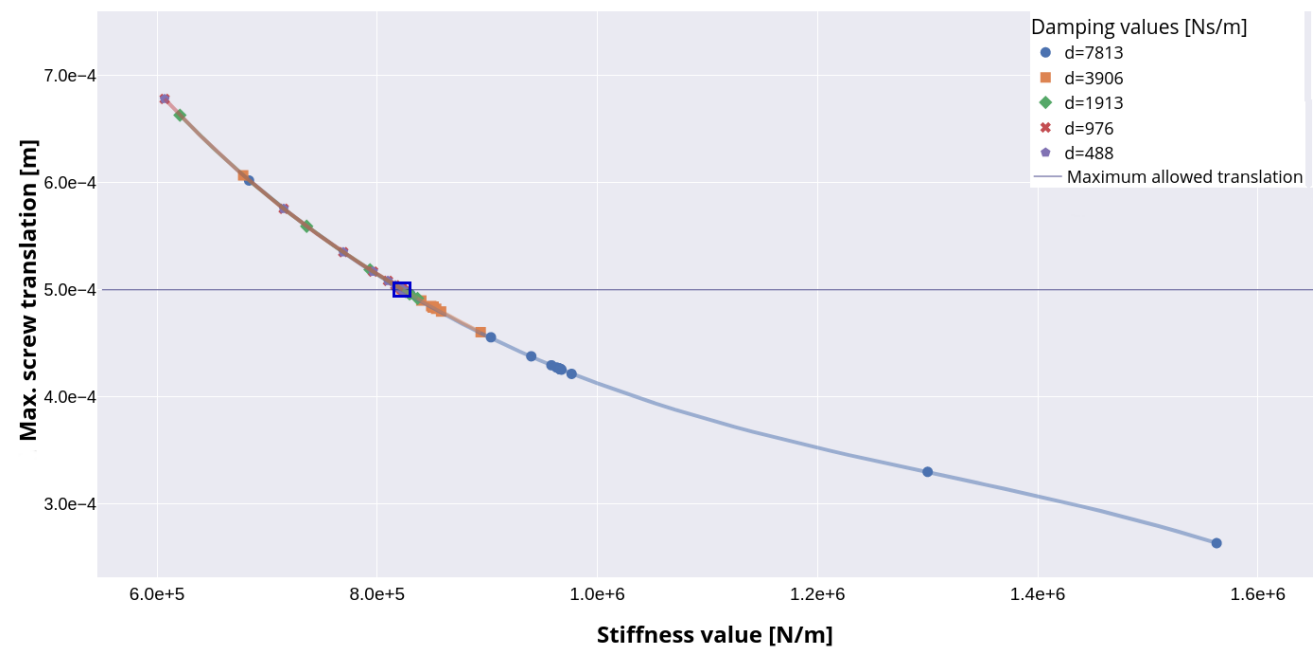

Figure 10. Result of the parameter optimization using binary search: the maximum screw translation values are given for different selected damping and stiffness values. The curves connecting data points represent the corresponding regression curves. Screw displacement for optimal parameters is marked using the blue frame.

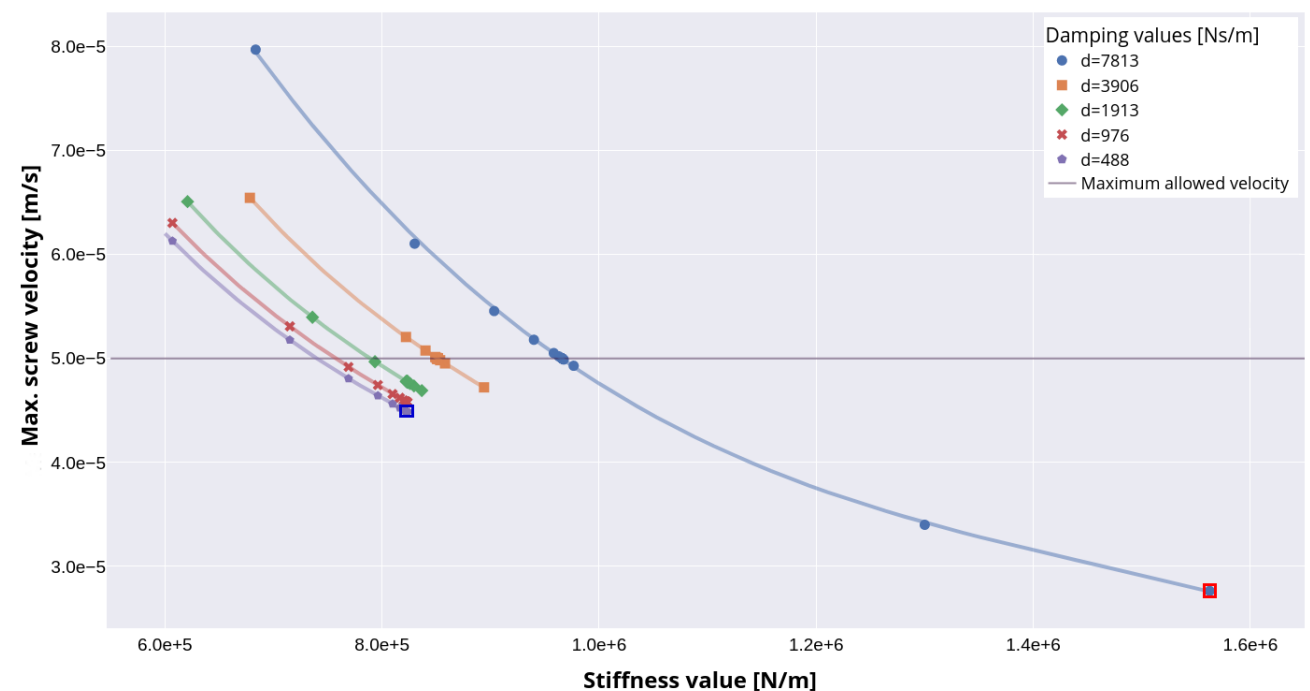

Figure 11. Result of parameter optimization using binary search: maximum screw velocity values are given for different damping and stiffness values. Curves connecting data points represent corresponding regression curves. 


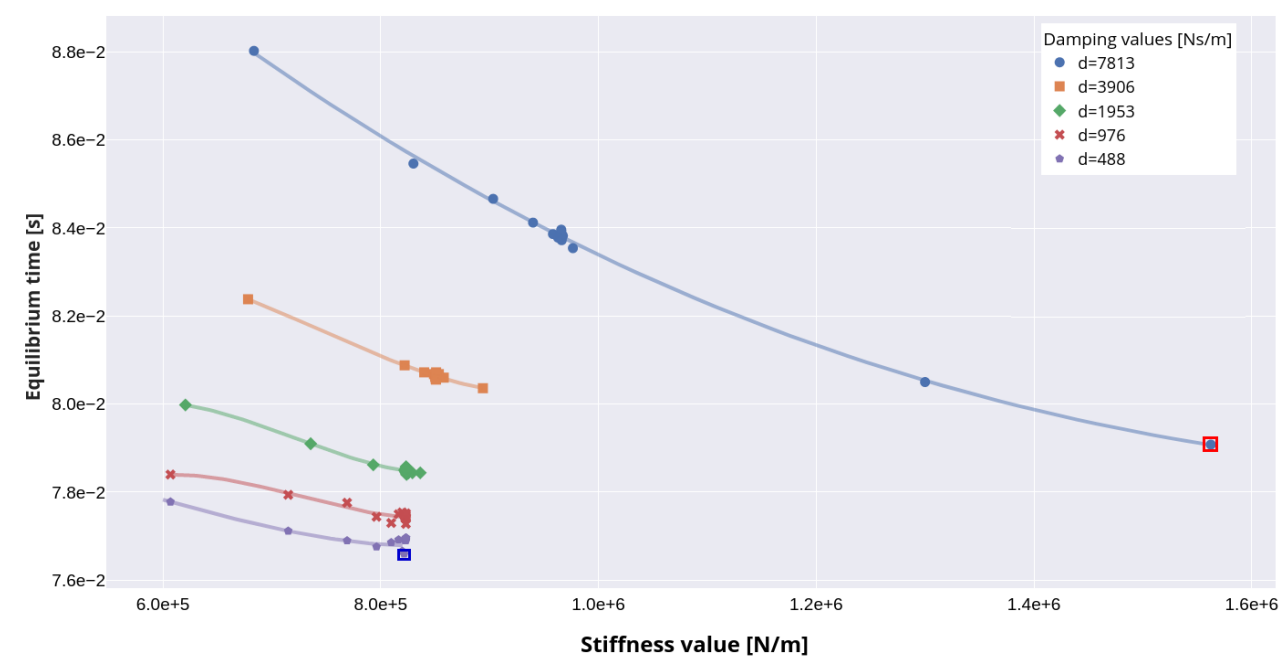

Figure 12. Result of parameter optimization using binary search: time the screw needs to reach a static equilibrium state for different damping and stiffness values.

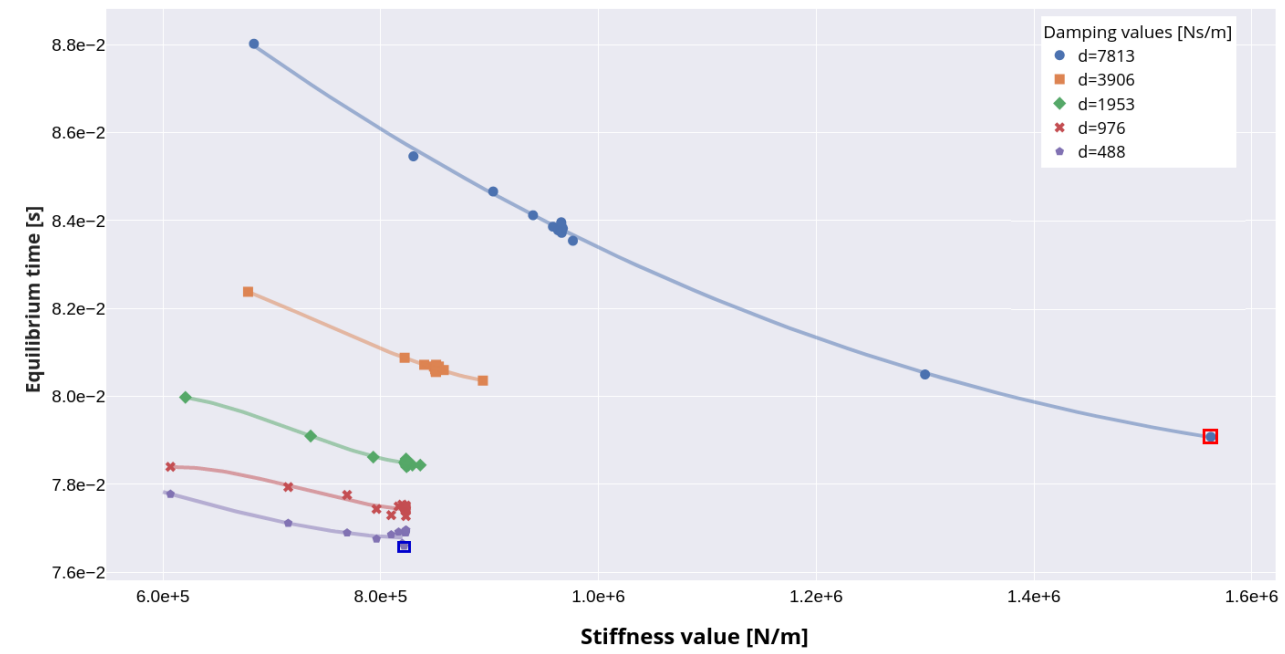

Figure 13. Result of parameter optimization using binary search: time the screw needs to reach a static equilibrium state for different damping and stiffness values.

\section{Author Contributions:}

Methodology, I.K.: S.B.

Validation: S.B.

Model creation: S.B.

Sensitivity Analysis Script creation: I.K.

Writing Original Draft Preparation: I.K., S.B.

Writing Review and Editing: I.K., S.B.

Project Administration: I.K., S.B.

Data Availability Statement: Not applicable

Acknowledgments: We would like to thank Mr. Claus Wenzler for fruitful discussions as well as providing data sets and corresponding material information.

Conflicts of Interest: The authors declare no conflict of interest

\section{Abbreviations}


The following abbreviations are used in this manuscript:

$\begin{array}{ll}\text { MBS } & \text { multibody simulation } \\ \text { FE } & \text { finite element } \\ \text { ATPS } & \text { anterior transpedicular screw } \\ \text { BMD } & \text { bone mineral densities } \\ \text { ASCF } & \text { ankylosing spondylitis cervical spine fractures } \\ \text { AVBS } & \text { artificial vertebral body system } \\ \text { ASPS } & \text { anterior screw plate system } \\ \text { SA } & \text { Sensitivity Analysis }\end{array}$

\section{References}

1. Wu, W.; Chen, C.; Ning, J.; Sun, P.D.; Zhang, J.; Wu, C.; Bi, Z.; Fan, J.; Lai, X.; Ouyang, J. A Novel Anterior Transpedicular Screw Artificial Vertebral Body System for Lower Cervical Spine Fixation: A Finite Element Study. Journal of biomechanical engineering 2017, 139. doi:10.1115/1.4036393.

2. Naoum, S.; Vasiliadis, A.V.; Koutserimpas, C.; Mylonakis, N.; Kotsapas, M.; Katakalos, K. Journal of Functional Biomaterials 2021, 12. doi:10.3390/jfb12030043.

3. Rosa, G.L.; Clienti, C.; Mineo, R.; Audenino, A. Experimental analysis of pedicle screws. Procedia Structural Integrity 2016, 2, 12441251. 21st European Conference on Fracture, ECF21, 20-24 June 2016, Catania, Italy, doi:https:/ / doi.org/10.1016/j.prostr.2016.06.159

4. Koktekir, E.; Toktas, Z.O.; Seker, A.; Akakin, A.; Konya, D.; Kilic, T. Anterior transpedicular screw fixation of cervical spine: Is it safe? Morphological feasibility, technical properties, and accuracy of manual insertion. Journal of neurosurgery. Spine 2015, 22, 596-604.

5. Reitman, C.; Nguyen, L.; Fogel, G. Biomechanical evaluation of relationship of screw pullout strength, insertional torque, and bone mineral density in the cervical spine. Journal of Spinal Disorders and Techniques 2004, 17, 306-311. doi:10.1097/01.bsd.0000090575.08296.9d.

6. Koller, H.; Acosta, F.; Tauber, M.; Fox, M.; Hudelmaier, M.; Forstner, R.; Augat, P.; Penzkofer, R.; Pirich, C.; Kässmann, H.; et al. Cervical anterior transpedicular screw fixation (ATPS) - Part II. Accuracy of manual insertion and pull-out strength of ATPS. European spine journal : official publication of the European Spine Society, the European Spinal Deformity Society, and the European Section of the Cervical Spine Research Society 2008, 17, 539-55. doi:10.1007/s00586-007-0573-x.

7. Becker, Y.N.; Motsch, N.; Hausmann, J.; Breuer, U.P. Hybrid composite pedicle screw - finite element modelling with parametric optimization. Informatics in Medicine Unlocked 2020, 18, 100290. doi:https:/ /doi.org/10.1016/j.imu.2020.100290.

8. Mas, Y.; Gracia, L.; Ibarz, E.; Gabarre, S.; Pena, D.; Herrera, A. Finite element simulation and clinical follow-up of lumbar spine biomechanics with dynamic fixations. PloS one 2017, 12, 1-19.

9. Schmidt, H.; Heuer, F.; Wilke, H.J. Which axial and bending stiffnesses of posterior implants are required to design a flexible lumbar stabilization system? Journal of Biomechanics 2009, 42, 48-54.

10. Goel, V.K.; Grauer, J.; Patel, T.; Biyani, A.; Sairyo, K.; Vishnubhotla, S.; Matyas, A.; Cowgill, I.; Shaw, M.; Long, R.; et al. Effects of Charite artificial disc on the implanted and adjacent spinal segments mechanics using a hybrid testing protocol. Spine 2005, 30, 2755-64.

11. Sun, J.; Wang, Q.; Cai, D.; Gu, W.; Ma, Y.; Sun, Y.; Wei, Y.; Yuan, F. A lattice topology optimization of cervical interbody fusion cage and finite element comparison with ZK60 and Ti-6Al-4V cages. BMC Musculoskeletal Disorders 2021, 22. doi:10.1186/s12891021-04244-2.

12. Galbusera, F.; Bellini, C.M.; Costa, F.; Assietti, R.; Fornari, M. Anterior cervical fusion: a biomechanical comparison of 4 techniques: Laboratory investigation. Journal of Neurosurgery: Spine SPI 2008, 9, 444-449. doi:10.3171/SPI.2008.9.11.444.

13. Liu, S.; Qi, W.; Zhang, Y.; Wu, Z.; Yan, Y.B.; Lei, W. Effect of bone material properties on effective region in screw-bone model: an experimental and finite element study. BioMedical Engineering OnLine 2014, 13, 83-83.

14. Van den Abbeele, M.; Valiadis, J.M.; Lima, L.; Khalifé, P.; Rouch, P.; Skalli, W. Contribution to FE modeling for intraoperative pedicle screw strength prediction. Computer Methods in Biomechanics and Biomedical Engineering 2017, 21, 1-9. doi:10.1080/10255842.2017.1414200.

15. Matsukawa Keitaro, Yato Yoshiyuki, I.H. Impact of Screw Diameter and Length on Pedicle Screw Fixation Strength in Osteoporotic Vertebrae: A Finite Element Analysis. Asian Spine J 2021, 15, 566-574, [http:/ / www.asianspinejournal.org/journal/view.php?number=1322 doi:10.31616/asj.2020.0353.

16. Qi, W.; Yan, Y.B.; Zhang, Y.; Lei, W.; jie Wang, P.; Hou, J. Study of stress distribution in pedicle screws along a continuum of diameters: a three dimensional finite element analysis. Orthopaedic Surgery 2011, 3.

17. Xu, M.; Yang, J.; Lieberman, I.H.; Haddas, R. Finite element method-based study of pedicle screw-bone connection in pullout test and physiological spinal loads. Medical Engineering Physics 2019,67,11-21. doi:https://doi.org/10.1016/j.medengphy.2019.03.004.

18. Su, K.C.; Chen, K.H.; Pan, C.C.; Lee, C.H. Biomechanical Evaluation of Cortical Bone Trajectory Fixation with Traditional Pedicle Screw in the Lumbar Spine: A Finite Element Study. Applied Sciences 2021, 11. doi:10.3390/app112210583. 
19. Sensale, M.; Vendeuvre, T.; Schilling, C.; Grupp, T.; Rochette, M.; Dall'Ara, E. Patient-Specific Finite Element Models of Posterior Pedicle Screw Fixation: Effect of Screw's Size and Geometry. Frontiers in Bioengineering and Biotechnology $2021,9,175$. doi:10.3389/fbioe.2021.643154.

20. Somtua1, C.; Aroonjarattham1and, P.; Aroonjarattham, K. Parametric study of pedicle screw: effect of stress transfer parameters on pullout strength. Asia-Pacific Journal of Science and Technology 2021, 26, 1-11. doi:10.14456/apst.2021.30.

21. Ritddech, S.; Aroonjarattham, P.; Aroonjarattham, K. The Effect of Screw Parameters on Pullout Strength of Screw Fixation in Cervical Spine. International Journal of Mechanical and Mechatronics Engineering 2015, 9, 247 - 250.

22. Bauer, S. Basics of Multibody Systems: Presented by Practical Simulation Examples of Spine Models. In Numerical Simulation; Lopez-Ruiz, R., Ed.; IntechOpen: Rijeka, 2016; chapter 2. doi:10.5772/62864.

23. Bonnheim, N.; Keaveny, T. Load-transfer in the human vertebral body following lumbar total disc arthroplasty: Effects of implant size and stiffness in axial compression and forward flexion 2020. 3, e1078. doi:10.1002/jsp2.1078.

24. Matsukawa, K.; Yato, Y.; Imabayashi, H. Impact of Screw Diameter and Length on Pedicle Screw Fixation Strength in Osteoporotic Vertebrae: A Finite Element Analysis. Asian Spine Journal 2021, 15, 566-574, [http:/ / www.asianspinejournal.org/journal/view.php?number doi:10.31616/asj.2020.0353.

25. Pezowicz, C.; Filipiak, J. Influence of loading history on the cervical screw pullout strength value. Acta of Bioengineering and Biomechanics 2009, 11, 35-40.

26. Van den Abbeele, M.; Valiadis, J.M.; Lima, L.; Khalifé, P.; Rouch, P.; Skalli, W. Contribution to FE modeling for intraoperative pedicle screw strength prediction. Computer Methods in Biomechanics and Biomedical Engineering 2017, 21, 1-9. doi:10.1080/10255842.2017.1414200.

27. Qiao, G.; Rahmatalla, S. Identification of damping and stiffness parameters of cervical and lumbar spines of supine humans under vertical whole-body vibration. Journal of Low Frequency Noise, Vibration and Active Control 2020, 39, 59-71.

28. Silvestros, P.; Preatoni, E.; Gill, H.S.; Gheduzzi, S.; Hernandez, B.A.; Holsgrove, T.P.; Cazzola, D. Musculoskeletal modelling of the human cervical spine for the investigation of injury mechanisms during axial impacts. PLoS one 2019, 14, e0216663.

29. Kassem, A.; Sameh, A. Lumbar Spine: Parameter Estimation for Realistic Modeling. WSEAS Transactions on Theoretical and Applied Mechanics, pp. 113-118.

30. Rohlmann, A.; Zander, T.; Bergmann, G.; Boustani, H.N. Optimal stiffness of a pedicle-screw-based motion preservation implant for the lumbar spine. European Spine Journal 2012, 21, 666-673.

31. Au-Yeung, K.Y.; Yang, B.; Sun, L.; Bai, K.; Yang, Z. Super Damping of Mechanical Vibrations. Scientific Reports 2019,9 , 17793. doi:10.1038/s41598-019-54343-3.

32. Van den Abbeele, M.; Valiadis, J.M.; Lima, L.V.; Khalifé, P.; Rouch, P.; Skalli, W. Contribution to FE modeling for intraoperative pedicle screw strength prediction. Computer methods in biomechanics and biomedical engineering 2018, 21, 13-21.

33. Zhang, Q.H.; Tan, S.H.; Chou, S.M. Effects of bone materials on the screw pull-out strength in human spine. Medical engineering $\mathcal{E}$ physics 2006, 28, 795-801.

34. Goldsmith, C.; Gafni, A.; Drummond, M.; Torrance, G.; Stoddart, G. Sensitivity Analysis and Experimental Design: The Case of Economic Evaluation of Health Care Programmes. Proceedings of the Third Canadian Conference on Health Economics 1986, 1986.

35. Saltelli, A.; Chan, K.; Scott, E. Sensitivity Analysis; Wiley, 2009.

36. Özkaya, N.; Leger, D.; Goldsheyder, D.; Nordin, M. Fundamentals of biomechanics: equilibrium, motion, and deformation; Springer, 2016.

37. Zander, T.; Dreischarf, M.; Timm, A.K.; Baumann, W.W.; Schmidt, H. Impact of material and morphological parameters on the mechanical response of the lumbar spine - A finite element sensitivity study. Journal of biomechanics 2017, 53, 185-190. doi:10.1016/j.jbiomech.2016.12.014.

38. Alizadeh, M.; Knapik, G.G.; Mageswaran, P.; Mendel, E.; Bourekas, E.; Marras, W.S. Biomechanical musculoskeletal models of the cervical spine: A systematic literature review. Clinical Biomechanics 2020, 71, 115 - 124. doi:https:/ /doi.org/10.1016/j.clinbiomech.2019.10.02 